\title{
High Performance Phenol Degrading Microorganisms Isolated from Wastewater and Oil-Contaminated Soil
}

\author{
Mailin, M. and Firdausi, R.* \\ Department of Bioprocess Engineering, Faculty of Chemical and Natural Resources Engineering, \\ Universiti Teknologi Malaysia, 81310 UTM Skudai, Johor \\ E-mail: firdaus@fkkksa.utm.my
}

\begin{abstract}
Four bacteria, two each isolated from wastewater treatment and oil-contaminated soil showed great potential as phenol degraders. RWC-Cr1, the isolate from wastewater was not only demonstrating the highest specific phenol degradation rate at all tested phenol concentrations, but also not affected by the highest phenol concentration employed, namely $1000 \mathrm{mg} / \mathrm{l}$. After a serial transfer of all four isolates into a series of increasing phenol level, all but RWC-Cr1 demonstrated significant improvement on degradation ability. ISC-Tra which was isolated from oil-contaminated soil exhibited greatest improvement (e.g. $750 \%$ at $600 \mathrm{mg} / \mathrm{l}$ phenol) after adaptation in phenol. Thus, the ISC-Tra was the most acclimatizable isolate while in contrary RWC-Cr1 was not significantly influenced by acclimatization. Outcomes of this study offer a useful guideline in evaluating potential phenol degraders from the environment.
\end{abstract}

Keywords: Phenol, Degradation, Bacteria, Wastewater, Acclimatization

\section{INTRODUCTION}

During the last few decades, an array of foreign compounds has been introduced into the environment due to the revolution of industrial field. The accumulation of these compounds has resulted in environmental contamination and contributed to many deleterious effects on living systems. The need to remove these contaminations has led to the development of new technologies with different removal performance and cost levels. Traditionally, wastewaters were treated by physicochemical methods, but recently biodegradation has been widely studied and used as a low-cost alternative and offering the possibility of complete mineralization of organic compounds (Collins and Daugulis 1997).

A wide spectrum of recalcitrant compounds has been shown to be biodegradable at laboratory scales. Currently, biodegradation of aromatic compounds received a great attention from many industrialists and researches due to their toxicity and refractory. Among all those aromatic compounds, phenol and their derivatives are known as a common constituent of wastewater originating from many industries including pharmaceutical, petroleum, oil refineries, textiles and coal refining (Nuhoglu and Yalcin, 2004). The toxicity of phenol has been widely documented and their disastrous effect toward human and environment is greatly concerned (Hannaford and Kuek, 1999; Chen et al., 2002; Prieto et al., 2002).

Many aerobic bacteria are capable of using aromatic compounds as their sole carbon source and energy (Wang and Loh, 1999). The biological degradation is accomplished through benzene ring cleavage mediated by

\section{${ }^{*}$ Corresponding author}

intracellular enzymatic reaction (Kumar et al., 2004). The use of pure cultures, especially adapted to metabolize the contaminant, can be envisaged as an attractive alternative (Nurdan and Azmi, 2004). The microorganisms that are normally used in phenol degradation include Pseudomonas sp (Nurdan and Azmi, 2004; Gonzalez et al., 2001; Monteiro et al., 2000), Candida tropicalis (Chen et al., 2002), Azotobacter sp (Hughes and Bayly, 1983), Rhodococcus sp (Prieto et al., 2002), Alcaligenes sp (Valenzuela et al., 1997), and Acinetobacter sp (Hao et al., 2002). Acclimatization of the microorganisms overcomes the substrate inhibition problems that normally occurred in phenol biodegradation at high concentration (Lob and Tar, 2000). Certain intracellular enzymes are induced during acclimatization stage so that the microbes are available to take part in the reaction (Kumar et al., 2004).

The study aimed to evaluate the potential of phenol degraders from environment. Phenol-degrading microorganisms were isolated and their performance in treating the compound was investigated.

\section{MATERIALS AND METHODS}

\section{Microorganisms}

Four pure cultures used in this study were isolated from industrial and residential wastewaters. It was maintained by periodic subculture on Nutrient Agar at $4^{\circ} \mathrm{C}$.

\section{Culture Medium}

Ramsay medium was used as a culture medium in this study (Ramsay et al., 1983). This medium was supplemented with $\mathrm{NH}_{4} \mathrm{NO}_{3}, 2.0 \mathrm{~g} / \mathrm{l} ; \mathrm{KH}_{2} \mathrm{PO}_{4}, 0.5 \mathrm{~g} / \mathrm{l}$; 
$\mathrm{K}_{2} \mathrm{HPO}_{4}, 1.0 \mathrm{~g} / \mathrm{l} ; \mathrm{MgSO}_{4} .7 \mathrm{H}_{2} \mathrm{O}, 0.5 \mathrm{~g} / \mathrm{l} ; \mathrm{CaCl}_{2} .2 \mathrm{H}_{2} \mathrm{O}, 0.01$ $\mathrm{g} / \mathrm{l} ; \mathrm{KCl}, 0.1 \mathrm{~g} / \mathrm{l}$; and Yeast extract, $0.06 \mathrm{~g} / \mathrm{l}$. The medium was autoclaved at $121^{\circ} \mathrm{C}$ for $15 \mathrm{~min}$ for sterilization. Phenol $(0.3 \mathrm{~g} / \mathrm{l})$ was separately sterilized by membrane filter before aseptically added into the sterile medium.

\section{Isolation of Bacterial Strains}

Samples were taken from residential wastewater treatment plant and industrial oil-contaminated soil. The samples were added into Ramsay medium containing 1 $\mathrm{g} / \mathrm{l}$ glucose as sole carbon source before incubation for 24 hours. The grown cultures were further treated with $0.3 \mathrm{~g} / \mathrm{l}$ phenol at room temperature for 24 hours and shaken at $150 \mathrm{rpm}$ (Infors AG, Switzerland). A volume of $0.1 \mathrm{ml}$ of the treated samples were serially diluted and spread evenly over the surface of Nutrient Agar using sterile glass spreader to get a single colony.

\section{Identification of Isolates}

The isolates were identified based on morphological observation and biochemical characterization. The tests involved were Gram staining, catalase, oxidase, urease, citrate and indole tests (Tortora et al., 2004; Benson, 1994; MacFaddin, 2000). Bergey's Manual of Determinative of Bacteriology was used as a reference to identify the isolates (Goodfeelow, 1994).

\section{Acclimatization}

The culture was grown in the medium containing glucose as carbon source for 24 hours and then $10 \%(\mathrm{v} / \mathrm{v})$ of them were transferred to sterile Ramsay medium containing 0.8 $\mathrm{g} / \mathrm{l}$ glucose and $0.2 \mathrm{~g} / \mathrm{l}$ phenol. The medium was agitated at $150 \mathrm{rpm}$ for 24 hours at room temperature. The cultures were further acclimatized to phenol by exposing the culture in a series of $250-\mathrm{ml}$ shake flasks, wherein the content of glucose was gradually decreasing while the concentration of phenol was gradually increasing.

\section{Analytical Method}

The biomass concentration was estimated by optical density measurement in $1 \mathrm{~cm}$ cuvettes at wavelength of $600 \mathrm{~nm}$ (Hannaford and Kuek, 1999) using UVspectrophotometer (Shimadzu). Phenol concentration in sample was assayed using the calorimetric method prescribed by Box (1981). Samples were taken both in the beginning and at the end of experiments for biomass and phenol assay. They were spinned at 10,000 rpm for 10 minutes to separate the biomass from the supernatant. An amount of $0.1 \mathrm{ml}$ of Folin-Ciocalteau reagent was added into the mixture of $2 \mathrm{ml}$ of the supernatant and $0.3 \mathrm{ml}$ of sodium carbonate $(200 \mathrm{~g} / \mathrm{l})$. The mixture was incubated for 60 minutes at room temperature to allow complete reaction and measured at $750 \mathrm{~nm}$ using spectrophotometer. A standard calibration curve was prepared with concentration of phenol in the range of $0-0.01 \mathrm{~g} / \mathrm{l}$.

\section{RESULTS AND DISCUSSION}

\section{Isolation and Identification}

Residential wastewater and industrial oil-contaminated soils were chosen as the sources of microorganisms in this study. High probability the presence of toxic pollutants in these sources was the reason why both sites were selected (Nuhoglu and Yalcin, 2004). Microorganisms that was previously adapted to toxic chemical capable of improving biodegradation process (Gonzalez et al., 2001). Therefore, indigenous microbes that were capable of treating various liquid toxic wastes might present at these sites.

The samples were enriched in sterile Ramsay medium supplemented with glucose as sole of carbon source to increase their density. During the enrichment stage, eight isolates were successfully isolated. The samples were further treated with phenol to ensure only phenol degraders would be selected (Mutzel et al., 1996). After the treatment, only four isolates survived, and identified as phenol degraders. The isolates were denoted as RWC-Sma, RWC-Cr1, ISC-Ycr and ISC-Tra (RWCResidential Wastewater Culture, ISC - Industrial Soil Culture).

The four isolates were morphologically and biochemically typified. RWC-Cr1 and RWC-Sma were both Gram negative in rod and cocci shape, respectively; while ISC-Ycr and ISC-Tra were both Gram negative cocci (Table 1). The results also indicated that all isolates were positive in oxidase and catalase tests. Hence, the microbes might be identified as an aerobic microorganism.

Table 1: Morphological and biochemical characterizations of isolates

\begin{tabular}{lcccc}
\hline \multirow{2}{*}{ Test } & \multicolumn{4}{c}{ Isolates } \\
\cline { 2 - 5 } & RWC-Sma & Rwc-Cr1 & ISC-Tra & ISC-Ycr \\
\hline Gram staining & - & - & - & - \\
Shape & rod & cocci & cocci & cocci \\
Catalase & + & + & + & + \\
Oxidase & + & + & + & + \\
Urease & - & - & - & - \\
Citrate & - & - & + & - \\
Indole & $+/-$ & $+/-$ & $+/-$ & + \\
\hline
\end{tabular}

According Bergey's Manual of Determinative of Bacteriology (MacFaddin, 2000), 85\% of the results showed the similarity characteristics with Pseudomonas $\mathrm{sp}$, Alcaligenes sp or Azotobacter sp. These results are consistent with previous reported studies (Hannaford and Kuek 1999; Hughes and Bayly, 1983; Moustafa, 2003).

\section{Experiments on Phenol}

The experiment aimed to find the highest tolerance level of phenol concentrations on four isolates. The decrease of glucose concentration was compensated by phenol to maintain $1000 \mathrm{mg} / \mathrm{l}$ total carbon sources. The tolerance 
level was based on how fast the phenol could be degraded. The results of the specific phenol degradation rate of all isolates are summarized in Figure 1. The specific degradation rate is defined based on the relationship between substrate consumption and the biomass growth within one hour in the fermentation process (Santos and Linardi, 2003). As all three other isolates demonstrated the specific degradation rate below $0.01 \mathrm{~g}$ phenol $/ \mathrm{g}$ cell per hour at all phenol concentrations, RWC-Cr1 continued to perform excellently even at 1000 $\mathrm{mg} / \mathrm{l}$ phenol. The increase in degradation rate by RWCCr1 obviously obeyed the first order kinetic, that the increase of rate is proportional to the initial concentration. Isolate RWC-Tr1 seemed to prefer phenol to glucose as carbon and energy source. Until further tests, we may conclude that the best phenol degrader candidate for future use is RWC-Cr1.

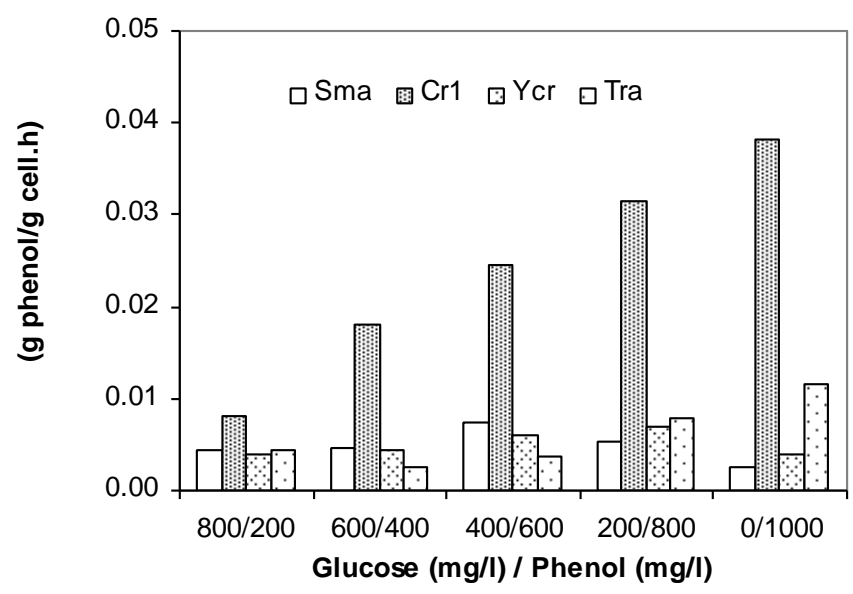

Figure 1: Specific phenol degradation rate by four isolates on different glucose to phenol ratios

The next experiment was to determine whether gradual acclimatization of all isolates on phenol might improve their degradation rate. During the acclimatization process, certain enzymes in bacteria are induced so that they are available to take part in the metabolism reaction (Kumar et al., 2004). Acclimatization also provides sufficient time for small populations of mineralizing organisms to become sufficiently large to bring a detectable loss of the chemical (Bruce et al., 1997). Each isolate was first grown in $100 \%$ glucose for 24 hours, and then $10 \%$ portion of them was transferred to medium with $200 \mathrm{mg} / \mathrm{l}$ and $800 \mathrm{mg} / \mathrm{l}$ phenol and glucose, respectively. The transfer continued until finally the cultures were grown only on phenol as a carbon source. Figure 2 summarizes the results of the specific phenol degradation rate of four isolates in different glucose to phenol ratios.

By comparing the data in Figure 1 and Figure 2, at least two major observations can be concluded. Firstly, while acclimatization did not result in marked changes on

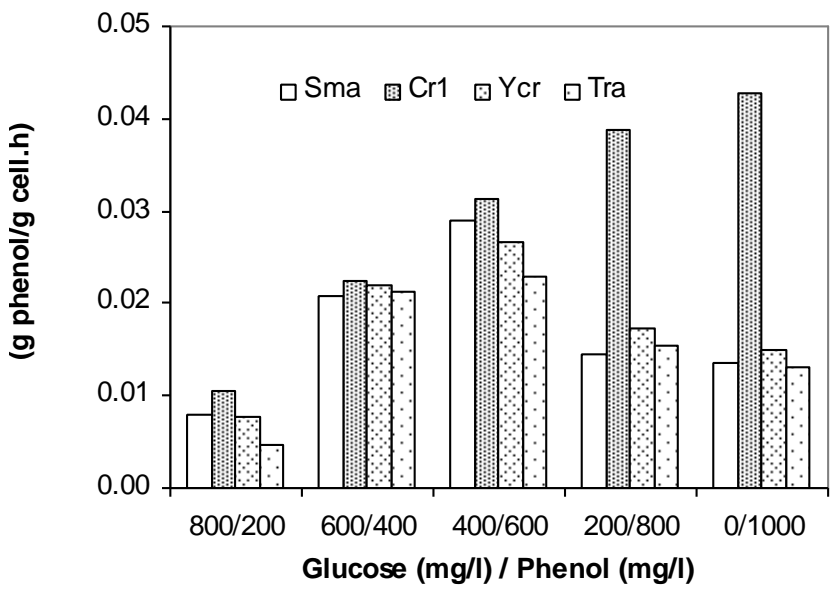

Figure 2: Phenol specific degradation rate by acclimatized cultures

RWC-Cr1, all three other isolates demonstrated encouraging improvement due to gradual exposure to phenol. The improvement may be best described by the percentage of change as illustrated in the histograms in Figure 3. The percentage of change is calculated by dividing the difference between values in Figure 2 and Figure 1 to values in Figure 1. Secondly, except for RWCCr1, acclimatization worked perfectly on three other isolates until phenol concentration reach at $600 \mathrm{mg} / \mathrm{l}$, however beyond this level, there was a gradual decrease of specific degradation. The similar inhibitory effect was also described by Monteiro et al., (2000). Data in Figure 3 also highlights that ISC-Tra was the most acclimatizable isolate (referring to $750 \%$ change at $600 \mathrm{mg} / \mathrm{l}$ phenol) as contrast to average $20-250 \%$ improvement for the rest, and acclimatization may not be necessary for RWC-Cr1.

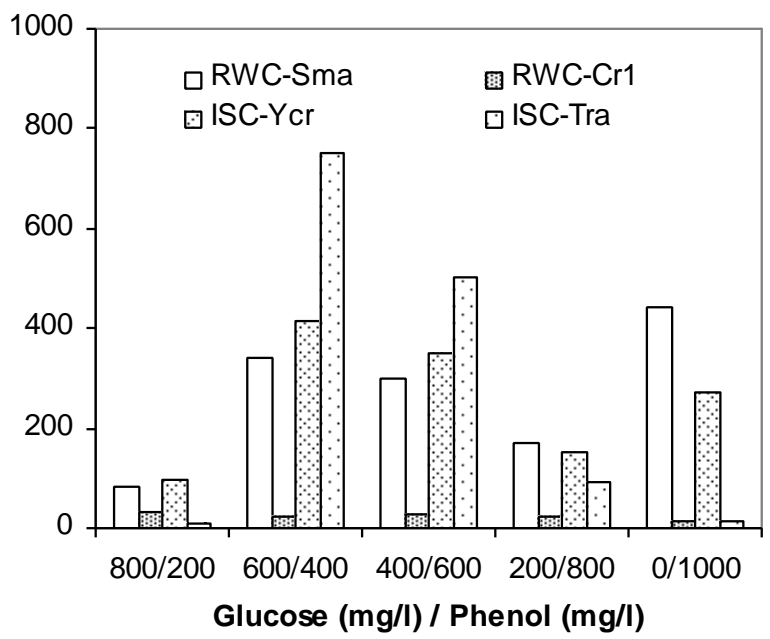

Figure 3: Percentage of change due to acclimatization 
Table 2: Reported studies on maximum phenol concentration used in both batch and continuous systems

\begin{tabular}{|c|c|c|c|c|}
\hline Author & Microorganism & System & $\begin{array}{l}\text { Phenol level } \\
\text { (mg/l) }\end{array}$ & $\begin{array}{c}\text { Specific growth rate, } \mu \\
\left(\mathrm{h}^{-1}\right)\end{array}$ \\
\hline $\begin{array}{l}\text { Hannaford and Kuek } \\
\text { (1999) }\end{array}$ & Pseudomonas putida & Batch & 1200 & NA \\
\hline Chen et al. (2002) & Candida tropicalis & Batch & 1000 & 0.01 \\
\hline This study (2006) & $\begin{array}{c}\text { RWC-Cr1 } \\
\text { (Pseudomonas sp, } \\
\text { Alcaligenes sp, or } \\
\text { Azotobacter sp) }\end{array}$ & Batch & 1000 & 0.09 \\
\hline Gonzalez et al. (2001) & Pseudomonas putida & Continuous & 1000 & 0.03 \\
\hline Chung et al. (2003) & Pseudomonas putida & Batch & 600 & 0.17 \\
\hline $\begin{array}{l}\text { Kumaran and Paruchuri } \\
\text { (1997) }\end{array}$ & Acinetobacter sp & Batch & 500 & NA \\
\hline Okaygun et al. (1992) & Klebsiella sp & Batch & 230 & NA \\
\hline Monteiro et al. (2000) & Pseudomonas putida & Batch & 100 & 0.16 \\
\hline
\end{tabular}

The superior of RWC-Cr1 in degrading $1000 \mathrm{mg} / \mathrm{l}$ phenol is comparable to other concentrations used in other studies as presented in Table 2. The isolate also demonstrated higher specific degradation rate, $\mu$ as compared to the reported data at same phenol level. It is important to notice that $1000 \mathrm{mg} / \mathrm{l}$ phenol tested on RWCCr1 was not the final tolerable level, since we have not yet tested it beyond this concentration. If work of Hannaford and Kuek (1999) to be bench marked, we expect that RWC-Cr1 can be challenged at $2000 \mathrm{mg} / \mathrm{l}$ or more.

\section{CONCLUSION}

Wastewater treatment plant and oil-contaminated soil are the most potential sources to isolate high performance phenol degrading microbes. Their degradation performance may be examined in a series of different phenol concentrations. Serial exposure to increasing level of phenol concentration can be used to determine acclimatizability of a particular isolates. Highly acclimatizable microbes or ones that are able to degrade phenol at highest concentration and at greatest rate will be the best phenol degrader candidates. This work has provided a useful guideline in evaluating potential phenol degraders isolated from environment.

\section{ACKNOWLEDEGEMENT}

This research was supported by UTM Short term Grant (vote no: 75200) and UTM-PTP Scholarship. The authors are grateful to the technicians and students in Department of Bioprocess Engineering for their contribution and technical supports in completing this study.

\section{REFERENCES}

Benson, H.J. (1994). Microbiology applications. $6^{\text {th }}$ edition. Brown Publishers. London.

Box, J.D. (1981). Investigation of the Folin-Ciocalteau Phenol Reagent for the Determination of Polyphenolic Substances in Natural Waters. Water Research 17:511-524.
Bruce, A.W., Stephen, H.J. amd Martin, A. (1987). Explanation fro the acclimation period preceeding the mineralization of organic chemical in aquatic environments. Applied and Environmental Microbiology 53:791-796.

Chang, Y.H., Li, C.T., Chang, M.C. and Shieh, W.K. (1998). Batch Phenol Degradation by Candida tropicalis and its Fusant.

Chen, K.C., Lin, Y.H., Chen, W.H. and Liu, Y.C. (2002). Degradation of phenol by PAA-immobilized Candida tropicalis. Enzyme and Microbial technology 31:490497.

Chung, T.P., Tseng, H.Y. and Juang, R.S. (2003). Mass transfer effect and intermediate detection for phenol degradation in immobilized Pseudomonas putida systems. Process Biochemistry 38: 1497-1507.

Collins, L.D. and Daugulis, A.J. (1997). Characterization and optimization of a two-phase partitioning bioreactor for the biodegradation of phenol. Applied Microbial Biotechnology 48: 18-22.

Gonzalez, G., Herrera, G., Garcia, M.T. and Pena, M. (2001). Biodegradation of phenolic industrial wastewater in a fluidized bed bioreactor with immobilized cells of Pseudomonas putida. Bioresource Technology 80: 137-142.

Goodfeelow M. (1994). Bergey's manual of determinative bacteriology $9^{\text {th }}$ edition. Williams and Wilkins. London.

Hannaford, A.M. and Kuek, C. (1999). Aerobic batch degradation of phenol using immobilized Pseudomonas putida. Journal of industrial microbiology and Biotechnology 22:121-126.

Hao, O.J., Kim, M.H, Seager, E.A. and Kim, H. (2002). Kinetics of Phenol and Chlorophenol Utilization by Acinetobacter species. Chemosphere 46: 797-807.

Hughes, E. J. and Bayly, R. C. (1983). Control of catechol meta cleavage pathway in Ralstonia eutropha. Journal Bacteriology 154: 1363-1370.

Kumar, A., Kumar, S. and Kumar, S. (2004). Biodegradation kinetics of phenol and cathecol using Pseudomonas putida 1194. Biochemical Engineering Journal 22: 151-159. 
Kumaran, P. and Paruchuri, Y.L. (1997). Kinetics of phenol biotransformation. Water Resource 31: 1122.

Lob, K.C. and Tar, P.P. (2000). Effect of Additional Carbon Source on Biodegradation of Phenol. Buletin of Environmental Contamination and Toxicology 64: 756-767.

MacFaddin, J.F. (2000). Biochemical test for identification of medical bacteria. Williams and Wilkins. London.

Monteiro, A.M.G., Boaventura, A.R. and Rodrigues, A.E. (2000). Phenol biodegradation by Pseudomonas putida DSM 548 in a batch reactor. Biochemistry Engineering. Journal 6:45-49.

Moustafa, E.A. (2003). Biological degradation of substrates mixtures composed of phenol, benzoat, acetate by Burkolderia cepacia G4. Dissertation Ph.D. University of Carolo-Wilhelmina, Germany.

Mutzel, A., Reinscheid, U.M., and Antranikian, G. and Muller, R. (1996). Isolation and characterization of a thermophilic bacillus strain, that degraded phenol and cresols as sole carbon source at $70^{\circ} \mathrm{C}$. 46:593-596.

Nuhoglu, A. and Yalcin, B. (2004). Modeling of phenol removal in a batch reactor. Process Biochemistry 1-7.

Nurdan, K.P., Azmi, T. (2005). Biodegradation of phenol by Pseudomonas putida immobilized on activated pumice particles. Process Biochemistry 40:18071814.

Okaygun, M.S., Green, L.A. andAkgerman, A. (1992). Effects of consecutive pulsing of an inhibitory substrate on biodegradation kinetics. Environment Science Technology 26:1746-1752.
Prieto, M.B., Hidalgo, A., Serra, J.L. and Llama, M.J. (2002). Degradation of phenol by Rhodococcus erythropolis UPV-1 immobilized on Biolite in a packed-bed reactor. Journal of Biotechnology 97:111.

Ramsay, B.A, Cooper, D.G. Margaritis, A. and Zajic, J.E. (1983). Rhodochorous Bacteria: Biosurfactant Production and Demulsifying Microbial Enhanced Oil Recovery 61-65.

Santos, V.L. and Linardi, V.R. (2003). Biodegradation of phenol by filamentous fungi isolated from industrial effluents-identification and degradation potential. Process Biochemistry 39:1001-1006.

Tortora, G.J., Funke, B.R. and Case, C.L (2004). Microbiology: An introduction. Pearson Benjamin Cumming. United State.

Valenzuela, J., Bumann, U., Cespedes, R., Padila, R. and Gonzalez, B. (1997). Degradation of chloropehnols by Alcaligenes eutrophus JMP134 (pJP4) in bleached kraft mill effluent. Applied Environment Microbiology 63:227-32.

Wang, S.J. and Loh, K.C. (1999). Modeling the role of metabolic intermediates in kinetic of phenol biodegradation. Enzyme and Microbial Technology 25:177-184. 